\title{
Freeform Laser Consolidated H13 and CPM 9V Tool Steels
}

\author{
L. Xue $\cdot$ J. Chen $\cdot$ S.-H. Wang
}

Received: 8 November 2012/Revised: 2 January 2013/Accepted: 7 January 2013/Published online: 25 January 2013

(C) Her Majesty the Queen in Right of Canada 2013

\begin{abstract}
As a novel computer-aided materials additive manufacturing process, the freeform laser consolidation (LC) can directly produce functional shapes (features or structures) through a "layer-upon-layer" deposition. In this research, LC processability of both H13 and CPM 9V tool steels and their mechanical performance thus obtained were investigated. Both laser-consolidated tool steels were metallurgically sound with no crack, exhibiting layer-wise refined solidified structures with dominated martensite and small amount of retained austenite, as well as compositiondependent carbides. Laser-consolidated H13 could outperform its wrought counterpart mechanically as measured by tensile strength/strain, and bonding strength as well as sliding wear resistance; laser-consolidated CPM 9V could provide excellent sliding wear resistance superior to the conventional widely used tool steel (such as wrought D2). These unique microstructures and mechanical properties could be tailored for niche applications in additive manufacturing of tools, molds, and dies.
\end{abstract}

Keywords Freeform laser consolidation - Additive manufacturing · Rapid tooling · AISI H13 - CPM 9V

\footnotetext{
L. Xue $(\bowtie) \cdot$ J. Chen

Automotive Portfolio, National Research Council of Canada, 800 Collip Circle, London, ON N6G 4X8, Canada

e-mail: lijue.xue@nrc.gc.ca

S.-H. Wang

Chalk River Laboratories, Atomic Energy of Canada Limited, Chalk River, ON K0J 1J0, Canada
}

\section{Introduction}

Tool, die, and mold (TDM) are one of the key enablers of automotive manufacturing to produce components and parts. Nowadays the automotive parts manufacturers are facing serious challenges to reduce the production cost of components and parts to maintain their global competitiveness. As the cost of TDM constitutes a substantial amount of the total production cost (about 5-50\% [1-3], depending on different manufacturing processes), TDM with a short development time, an overall low manufacturing cost and a relatively long service life, consequently, are highly desirable.

To that end, laser-cladding-based freeform fabrication $[4,5]$, which could directly fabricate functional shapes (features or structures) without molds and dies, presents a high potential on manufacturing of TDM; representative technologies of such kind include laser engineered net shaping $\left(\operatorname{LENS}^{\mathrm{TM}}\right)$ [6, 7], direct light fabrication (DLF) [8], direct metal deposition (DMD) [9, 10], laser direct casting (LDC) [11], and others which have been well documented [4, 5]. A lot of investigations have been reported to promote these processes for TDM materials development and rapid manufacturing by direct fabricating functional shapes or by enhancing, repairing, or re-configuring existing TDM with affordable cost [4-23]. However, it is also realized that some of these processes might only produce a "near-net" shape with rough surface finish and low-dimensional accuracy $[4,5,22,23]$ and, thus, post-machining is a must, which, more or less, could diminish the attractiveness of the processes.

In contrast, the freeform laser consolidation (LC) process, developed by National Research Council of Canada since mid-1990s, utilizes unique system configuration and process condition that enable direct fabrication of 
"net-shape" functional shapes with excellent surface finish and dimensional accuracy in one step [4, 24]. Compared with other similar freeform fabrication processes, the LC-produced shapes do not need or only require little postmachining, which provides an opportunity to fabricate complex three-dimensional shapes that are difficult or even impossible to fabricate by conventional manufacturing processes [25].

In this study, LC-produced AISI H13 and Crucible's CPM 9V tool steels were investigated since H13 steel represents a conventional hot-work tool steel [26, 27] mostly used to make TDM, while emerging CPM 9V tool steel has been increasingly used to manufacture high-performance TDM through conventional powder metallurgy (P/M) process [28]. H13 tool steel has already been widely investigated by LENS and DMD processes [9, 13, 17, 29, 30]. In contrast, CPM 9V steel belongs to a family of novel CPM tool steels, which possess substantially improved abrasive wear resistance in combination with enhanced toughness and heat check resistance due to the presence of a high amount of primary vanadium carbides in the matrix [28]. Only a few works such as in [12, 31-34] on laser deposition of CPM serial tool steels, however, have been reported so far since the high hardness of the steels might inevitably induce thermal cracking during the processes, especially in the case of freeform fabrication, bringing in a technical challenge to their material processability.

The objectives of this article are to present the solidified structures of LC-produced metallurgically sound H13 and CPM 9V tool steels, and their correlation with the mechanical performance thus obtained (such as tensile properties, sliding wear resistances, and interfacial bonding strengths) to investigate the feasibility of using both steels for manufacturing of TDM, since any success of the LC-processed steels would depend on the integrity of the materials as well as the functionalities of the shapes so produced.

\section{Experimental}

\section{Materials}

The commercial gas-atomized Micro-Melt ${ }^{\circledR}$ H13 powder (Carpenter Powder Products Inc., Bridgeville, PA) and Crucible's CPM 9V powder (Crucible Research Center, Pittsburgh, PA) were used as the LC materials. The powders were spherical in shape with a particle size range of about $15-45 \mu \mathrm{m}$. The chemical compositions of the respective powders are summarized in Table 1 . The hardened H13 tool steel and normalized AISI 4340 carbon steel plates with grounded surfaces were used as substrates for LC process development of H13 and CPM 9V powders, respectively.
Table 1 Chemical compositions of Micro-Melt ${ }^{\circledR}$ H13 and Crucible's CPM 9V powders (wt.\%)

\begin{tabular}{lll}
\hline Alloy & H13 & CPM 9V \\
\hline Carbon & 0.42 & 1.8 \\
Chromium & 5.04 & 5.35 \\
Manganese & 0.35 & 0.50 \\
Molybdenum & 1.33 & 1.24 \\
Copper & 0.02 & $\ldots$ \\
Silicon & 0.88 & 0.91 \\
Vanadium & 1.06 & 9.26 \\
Iron & Bal. & Bal. \\
\hline
\end{tabular}

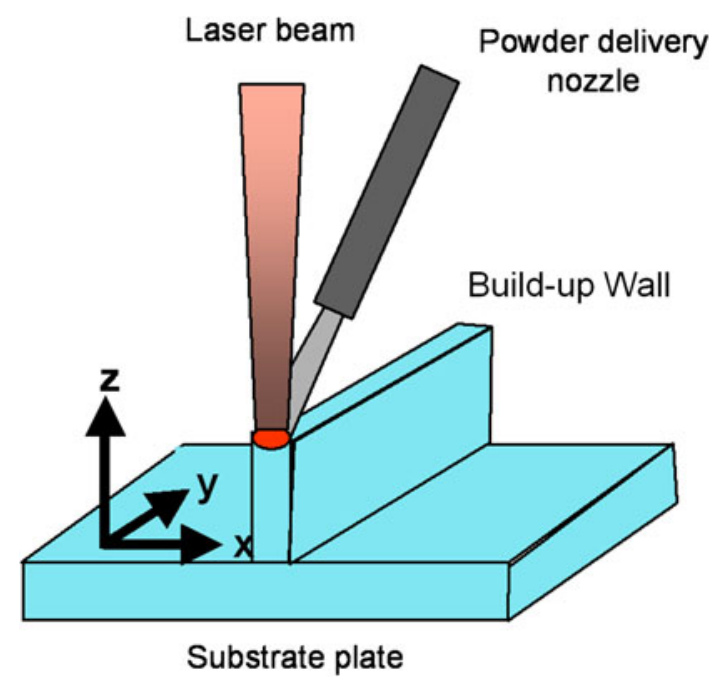

Fig. 1 An illustration of LC process

\section{LC Process}

The LC process with blown powder feeding was used for the present research. In the process setup as illustrated in Fig. 1, a $1 \mathrm{~kW}$ pulsed Nd:YAG laser in combination with a precision powder feeder and a numerically controlled (NC) motion system was utilized. The laser focusing optics and the powder feeding nozzle were installed on the $Z$-axis of the motion system, while one substrate was mounted on the $X-Y$ motion table. The LC process was carried out in a glove box filled with argon to maintain a low oxygen level $(<50 \mathrm{ppm}$, that is $0.005 \%)$; the argon was also used as carrying gas for the delivery of the alloy powders and shielding gas for the protection of the laser optics.

During the LC process, a laser beam was focused onto the substrate to create a molten pool (about $0.7 \mathrm{~mm}$ in diameter), while the steel powders (H13 or CPM 9V) were injected into the pool. With a traversing movement, the molten pool was travelling along controlled path, leaving the first deposited layer of the shape that was metallurgically bonded to the substrate. The successive layers were 
deposited on the top of the corresponding preceding layer through re-melting of a thin portion of that layer and re-solidified together with the injected powder, which would be continued until a desired shape, defined by a computer-aided model, was achieved. Some LC-produced H13 and CPM 9V shapes are presented in Fig. 2.

Figure 3 demonstrates some parts made by LC H13 and CPM 9V steels for potential TDM applications. A plastic injection mold insert was made by the LC H13-shell filled with backfilled material and with embedded multiple cooling channels inside (Fig. 3a); this would significantly reduce the cost for machining the cooling channels and enhance the cooling efficiency. A functional cutting pattern was made by the LC CPM 9V steel on low-cost AISI 4340 carbon steel substrate (Fig. 3b); this approach could produce a low-cost high-performance rotary cutting die [31] as compared with the same type of dies made entirely by AISI D2 tool steel, through conventional machining process.
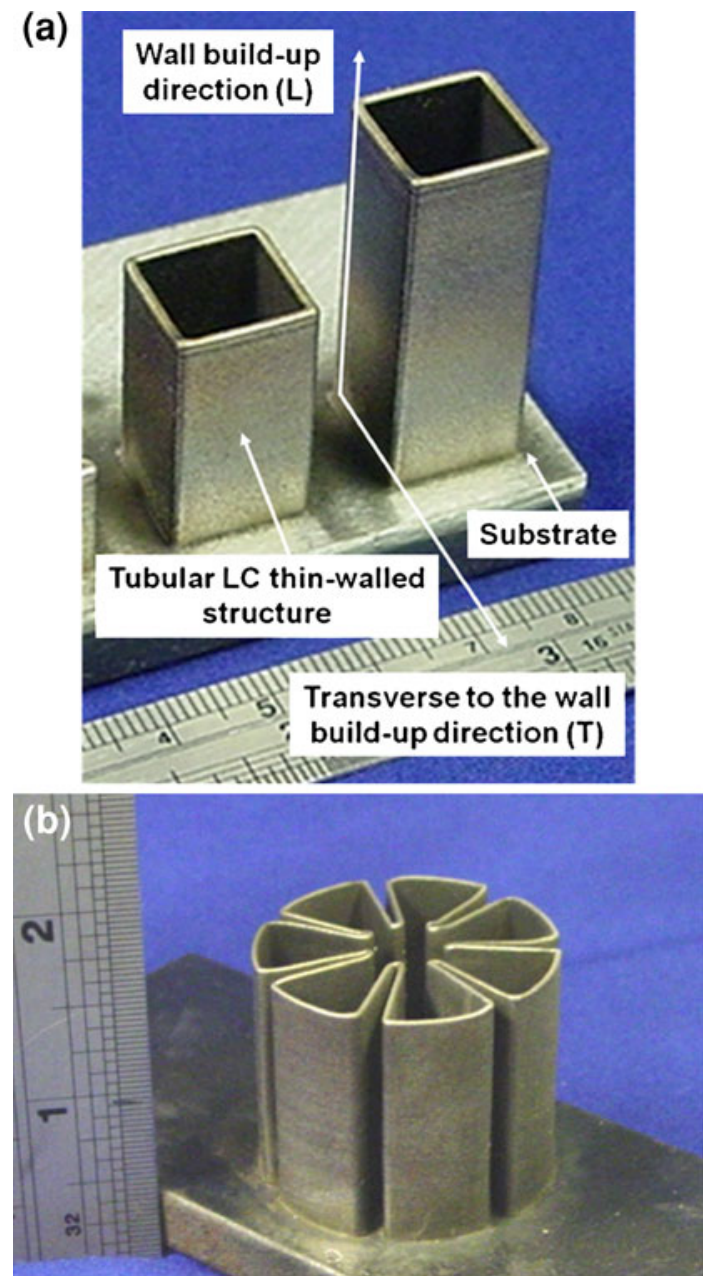

Fig. 2 LC shapes made by a H13 and b CPM 9V tool steels
Microstructural Characterization and Mechanical Properties

The microstructures of LC specimens were characterized by a light microscope (LM), a scanning electron microscope (SEM), and by an X-ray energy dispersive spectrometer (EDS). A X'Pert X-ray diffractometer (XRD) with graphitemonochromatic $\mathrm{Cu} \mathrm{K}$ radiation $(\lambda=0.15418 \mathrm{~nm})$ was used for phase identification. To reveal their types, carbides were extracted by an electrochemical anodic dissolution method.

The hardness of the LC tool steels was measured using a Rockwell hardness testing system. The microhardness profiles across the interfaces between LC steels and substrates were measured with a microhardness testing system using a Vickers indentor under a load of $2.94 \mathrm{~N}$ for $15 \mathrm{~s}$. The hardness data were averaged on three to five measurements.

The tensile testing was performed by employing a $100 \mathrm{kN}$ Instron's servo-hydraulic system. Flat tensile coupons (as per ASTM Standard E8M-97) were machined using the hollow rectangular LC thin-wall tubes built vertically on the substrate. The surfaces of the coupons within the area of the gage length were polished with 600-grit sand paper.
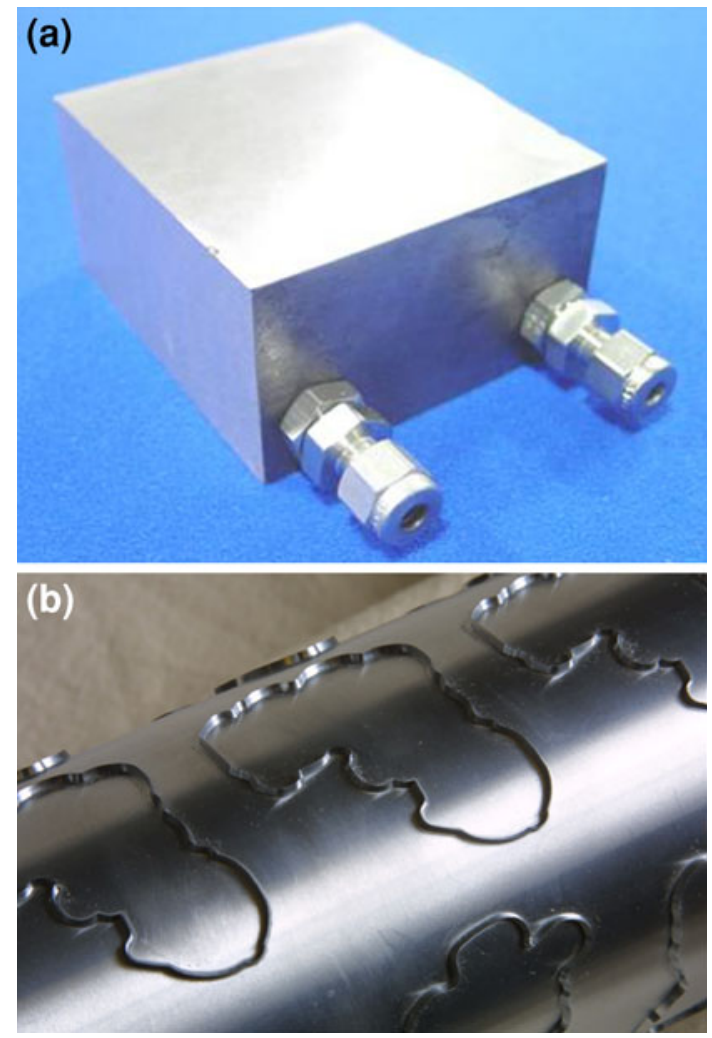

Fig. 3 LC process for TDM. a A plastic injection mold insert made by LC H13-shell filled with backfilled material which was embedded with multiple cooling channels inside and $\mathbf{b}$ a functional LC CPM 9V made cutting pattern on low-cost AISI 4340 carbon steel substrate for a rotary cutting die 


\section{Wear Testing}

Sliding wear resistance was evaluated as per ASTM Standard G99 by using a "Pin-on-Disc" system.

For the LC H13 steel (about HRC 55), a 1/4" (6.35 mm) diameter $\mathrm{Cr}$ steel ball (with a hardness of about HRC 63 and a chemical composition close to AISI 52100 steel) was mounted at the end of the "pin" and was pressed against the flat LC coupon with a load of $2.45 \mathrm{~N}$ during the wear testing. The total wear distance was $4000 \mathrm{~m}$ at a linear speed of $0.105 \mathrm{~m} / \mathrm{s}$. For comparison, wear tests were also performed on specimens of wrought $\mathrm{H} 13$ steel with various heat treatments as well as on specimens of LC H13 steel after tempering at various temperatures.

For the LC CPM 9V steel (about HRC 49), a $1 / 4$ " (6.35 mm) diameter WC-6 wt.\% Co ball (about HRC 92) was used as the counter-body under a load of $4.90 \mathrm{~N}$. The total running distance was about $8000 \mathrm{~m}$ at a linear speed of $0.28 \mathrm{~m} / \mathrm{s}$. For comparison, wear tests were performed on coupons of normalized AISI 4340 carbon steel (about HRC 35) and hardened D2 tool steel (about HRC 62) as well.

The volumetric wear loss was evaluated by measuring wear scar following the ASTM standard; the wear scar was evaluated with a surface profiler, and eight measurements were made along each wear scar for statistic purpose. The amounts of wear in the corresponding counter-bodies were determined by measuring the diameter of the circular wear scars on the balls to calculate their volumetric losses.

\section{Interfacial Bonding Evaluation}

For the LC H13 steel deposited onto the wrought H13 steel substrate, the interfacial bonding strength was characterized by pulling about $1 \mathrm{~mm}$ thick LC cylindrical thin-wall tube (with the size of about $14 \mathrm{~mm}$ in diameter and about $57 \mathrm{~mm}$ long) from the bonded wrought substrate, using a $100 \mathrm{kN}$ Instron mechanical testing system. The result would reflect a certain level of static bonding strength.

On the other hand, for the LC CPM 9V steel deposited onto the 4340 carbon steel substrate, to simulate the circumstance of the current application (a cutting die), the dynamic interfacial bonding behavior was evaluated by a custom-made impact testing apparatus (Fig. 4a).

During the testing, the LC thin-wall cutting blade (or blade) was tightly secured horizontally in the cavity of the apparatus (Fig. 4b). A cylindrical drop weight following a guide rod was allowed to fall freely to impact vertically the rectangular-shaped shearing hammer (placed close to the interfacial bondline), transferring its potential energy to the LC thin-wall blade in the normal direction. The potential energy $\left(\mathrm{J} / \mathrm{cm}^{2}\right)$ of the mass (cylindrical drop weight) prior to the impact was estimated by multiplying the drop distance
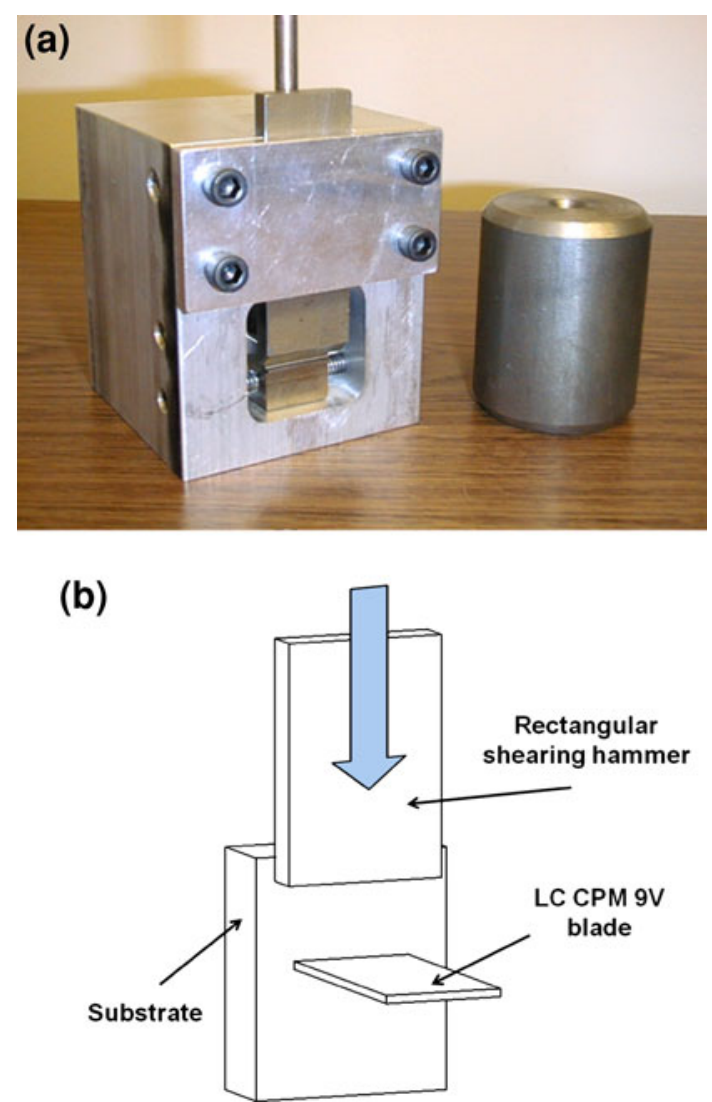

Fig. 4 a A custom-made impact apparatus for dynamic bonding strength testing; and $\mathbf{b}$ an illustration of the setup for testing a thin wall blade

with the mass of the drop weight and then divided by the cross-sectional area of the LC thin-wall blade.

The critical impact energy $\left(\mathrm{J} / \mathrm{cm}^{2}\right)$, which was defined as a minimum energy required for completely tearing off the bonded blade, indirectly reflected the interfacial dynamic bonding strength between the LC shape and the substrate.

\section{Results and Discussion}

Metallographic Characteristics of "As-Consolidated" Tool Steels

\section{Solidified Morphologies}

Both "as-consolidated" thin-wall H13 and CPM 9V steels sectioned along the wall build-up direction exhibit layerwise morphologies, which exactly reflect the nature of a "layer-upon-layer" deposition process.

More closely, each deposited layer of the LC H13 steel actually contains two sub-layers (Fig. 5a): one with fine equiaxed cells (accounting for about $25 \%$ of the whole layer) 

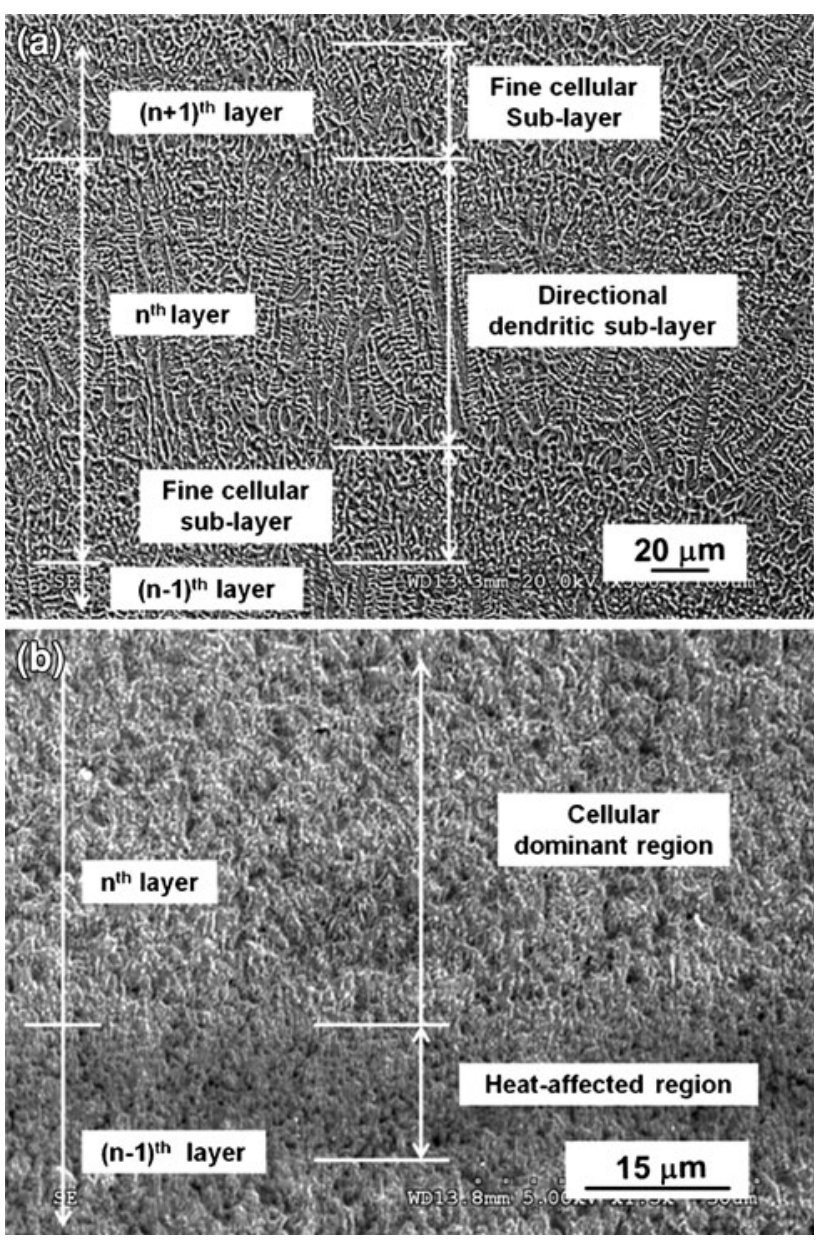

Fig. 5 Layer-wise morphologies of solidified structures in "asconsolidated" a H13 and b CPM 9V tool steels sectioned along the wall build-up direction

followed by another one with dominated directionally solidified dendrites (about $75 \%$ of the layer). The solidified structure was discontinued between two adjacent layers. Comparatively, each deposited layer of the LC CPM 9V steel was dominated by refined equiaxed cellular structure mixed with a very low amount of dendritic structure. A slightly "dark" region, revealed by SEM, could be identified at the top of each deposited layer (Fig. 5b).

\section{Phases and Microstructures}

Both "as-consolidated" steels could be characterized by dominating martensitic $\alpha^{\prime}$ phase, with the presence of a small amount of retained austenitic $\gamma^{\prime}$ phase as well as composition-dependent carbides (Fig. 6). A weak preferred orientation was observed in the XRD pattern of the martensitic phase (Fig. 6a) in the "as-consolidated" H13 steel (which could inherent from the parent austenitic phase): a slightly higher $\left.I_{\alpha^{\prime}(110)}\right) / I_{\alpha^{\prime}(200)}$ ratio (about 7.1) in the LC form than the corresponding one (about 5.7) in powder
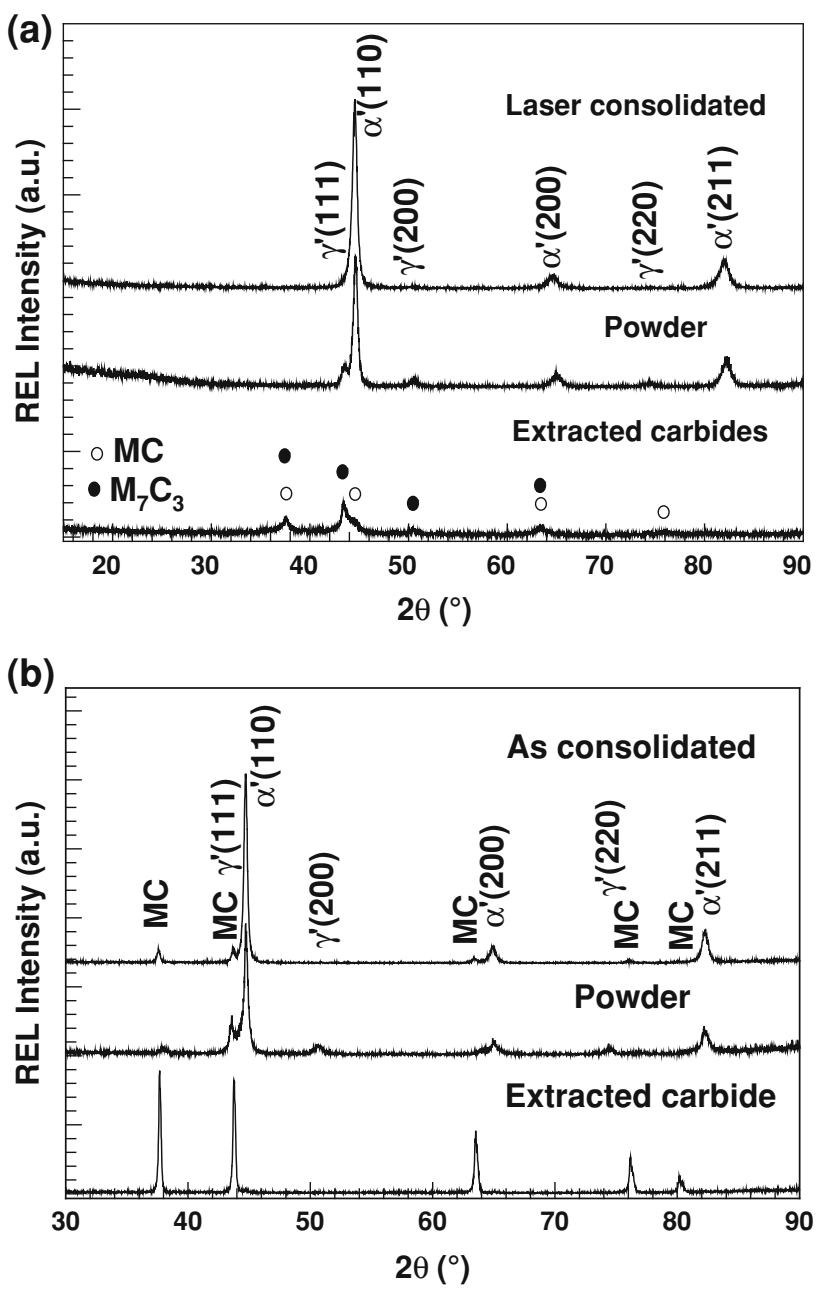

Fig. 6 XRD patterns of "as-consolidated" a H13 and b CPM 9V tool steels sectioned along the wall build-up direction, including chemically extracted carbides from the LC tool steels and the powders $(\mathrm{Cu} \mathrm{K} \alpha)$

form due to locally directionally solidified dendrites (Fig. 5a). Unlike the LC H13 steel, the "as-consolidated" CPM 9V steel did not show any preferred orientation in its martensitic phase: no difference of $I_{\alpha^{\prime}(110)} / I_{\alpha^{\prime}(200)}$ ratios between the LC steel and the powder (Fig. 6b). An analysis of the carbides retrieved from both steels through an electrochemical extraction revealed the dominance of MC-type carbides in the LC H13 steel, plus a small amount of $\mathrm{M}_{7} \mathrm{C}_{3}$ carbides (Fig. 6a); in contrast, the LC CPM 9V steel only contained MC-type carbides (Fig. 6b).

On the SEM study, LC H13 steel was further revealed that locally directionally solidified dendrites were married with a martensitic characteristic matrix along the wall build-up direction (Fig. 7a); whereas the same dendrites were presented as "equiaxed cells" after transversely cross sectioned (Fig. 7b). The average second dendritic arm spacing (SDAS) and the center-to-center cell spacing (CS) were estimated to be about $2-3 \mu \mathrm{m}$. An EDS analysis 

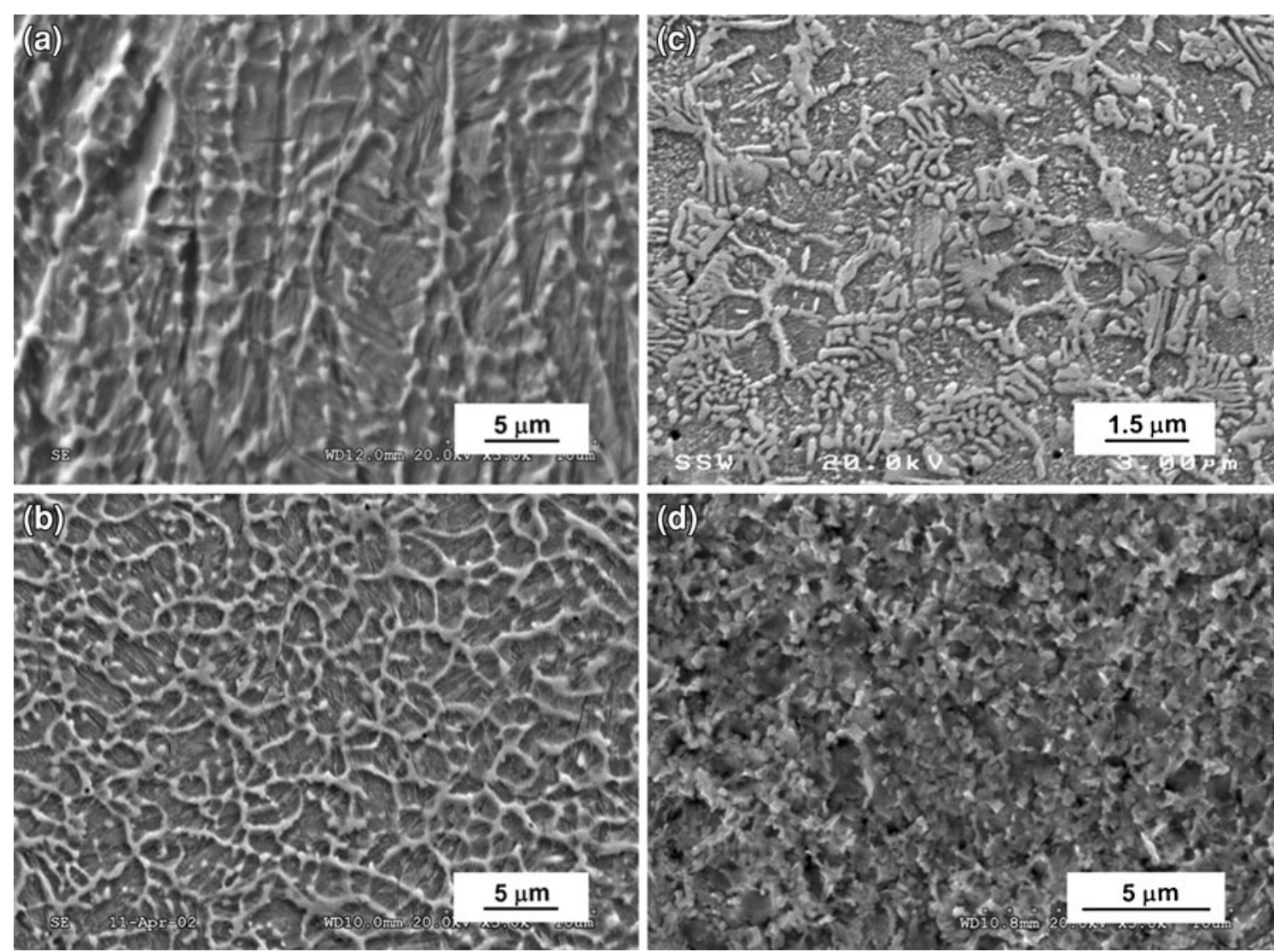

Fig. 7 a Directionally solidified dendrites of LC H13 steel sectioned along the wall build-up direction, and $\mathbf{b}$ cellular-like structure of LC H13 steel sectioned transverse to the wall build-up direction;

indicates that the $\mathrm{Cr}$ and $\mathrm{V}$ contents were richer at the interdendritic/inter-cellular regions (probably the presence of fine carbides) than the matrix. The fine microstructure implies that the LC H13 steel experienced a rapid solidification during the LC process.

The LC CPM 9V steel, in contrast, was revealed that equiaxed cellular structure on martensitic matrix $(1-1.5 \mu \mathrm{m}$ in diameter) was married with white, fine, and snowflake-like eutectic phases (only about $0.1 \mu \mathrm{m}$ wide and $0.1-1.5 \mu \mathrm{m}$ long) along the wall build-up direction (Fig. 7c). An EDS analysis revealed that $\mathrm{Cr}$ and $\mathrm{V}$ contents in the eutectic phase were higher than in the matrix, possibly due to the presence of primary MC-carbides. In addition, the microstructure in the slightly "dark" regions shows partially dissolved eutectic phase at the inter-cellular regions (Fig. 7d).

\section{LC Wall/Substrate Interfaces}

Figure 8(a) exhibits solidified structure at and near an interface of the "as-consolidated" thin-wall H13 steel deposited on a hardened wrought $\mathrm{H} 13$ substrate, where a sound metallurgical bond has been formed. The nuclei c dominant cellular structure in LC CPM 9V steel, and d microstructure at the slightly "dark" regions of LC CPM 9V steel sectioned along the wall build-up direction

were formed at the interface and grew as cells and then developed into dendrites toward the LC thin wall. The depth of the penetration (or dilution) was around $80 \mu \mathrm{m}$, which was substantially lower than any conventional welding (in a range of several millimeters instead). The heat-affected zone (HAZ) in the substrate was around $200 \mu \mathrm{m}$ deep. The profile of microhardness across the interface of the LC thin wall and the wrought substrate is presented in Fig. 8(b). The transition from the LC portion to the substrate went quite smooth, with no significant "soft" zone.

For the interface of the LC CPM 9V steel onto a normalized 4340 carbon steel substrate (Fig. 8c), the depth of the penetration was about $100 \mu \mathrm{m}$, while the thickness of the HAZ in the substrate was about $200 \mu \mathrm{m}$ (Fig. 8d). The interfacial bonding between the LC thin wall and the substrate was metallurgical sound as well. In contrast to the equiaxed cellular structure found in the majority of the LC thin wall, both extremely fine cells and directionally solidified dendrites were observed near the interface. The directionally solidified dendritic structure only existed at the initial several deposited layers and then gradually transited into relatively coarser equiaxed cellular-dominant 
(a)

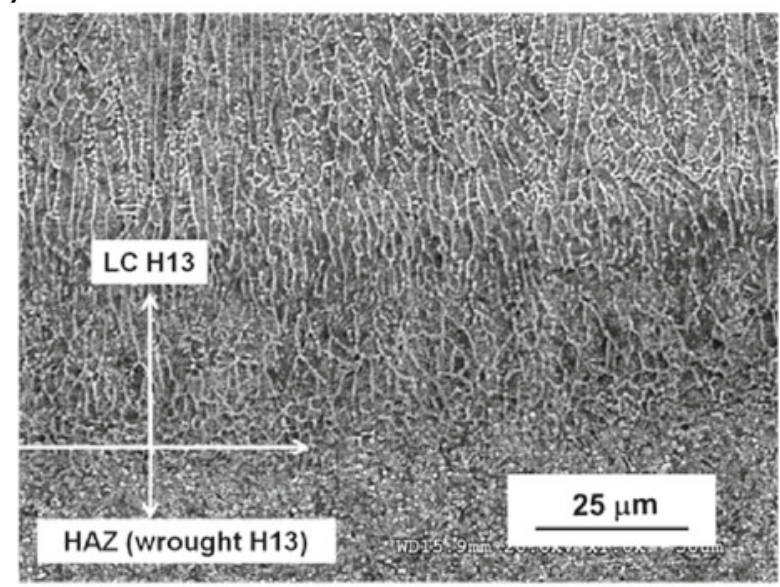

(b) 1000

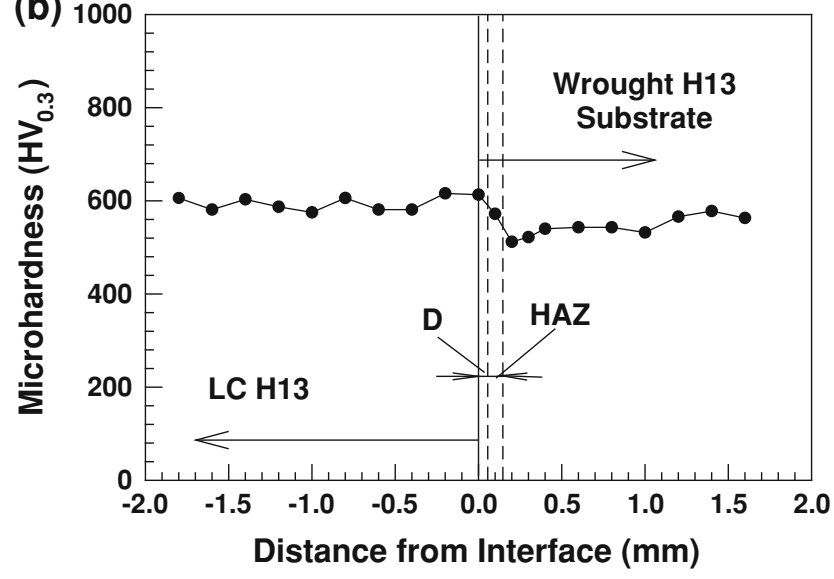

Fig. 8 a Microstructure and b profile of "as-consolidated" H13 steel across the interface between the LC thin wall and the substrate; c microstructure and $\mathbf{d}$ profile of "as-consolidated" CPM 9V steel

structure (Fig. 7c). The profile of microhardness across the interface was measured (Fig. 8d) as well. The microhardness of the LC steel near the interface was substantially higher than the microhardness of the same LC material which was about $1.2 \mathrm{~mm}$ away from the interface. The higher microhardness of the LC steel near the interface might be ascribed to much fine dendrites (due to a more effective heat-sink effect from the substrate) as compared with the rest of the solidified CPM $9 \mathrm{~V}$ structure (due to a less effective heat-sink effect brought by the thin wall instead).

\section{Solidification Process}

During the solidification of a steel molten pool, the primary phase (ferritic $\delta$ or/and austenitic $\gamma$ ) mainly depends on its chemical composition (mainly carbon content) and surrounding solidification condition. When the tool steel contains carbon higher than roughly $1.3 \%$, the primary (c)
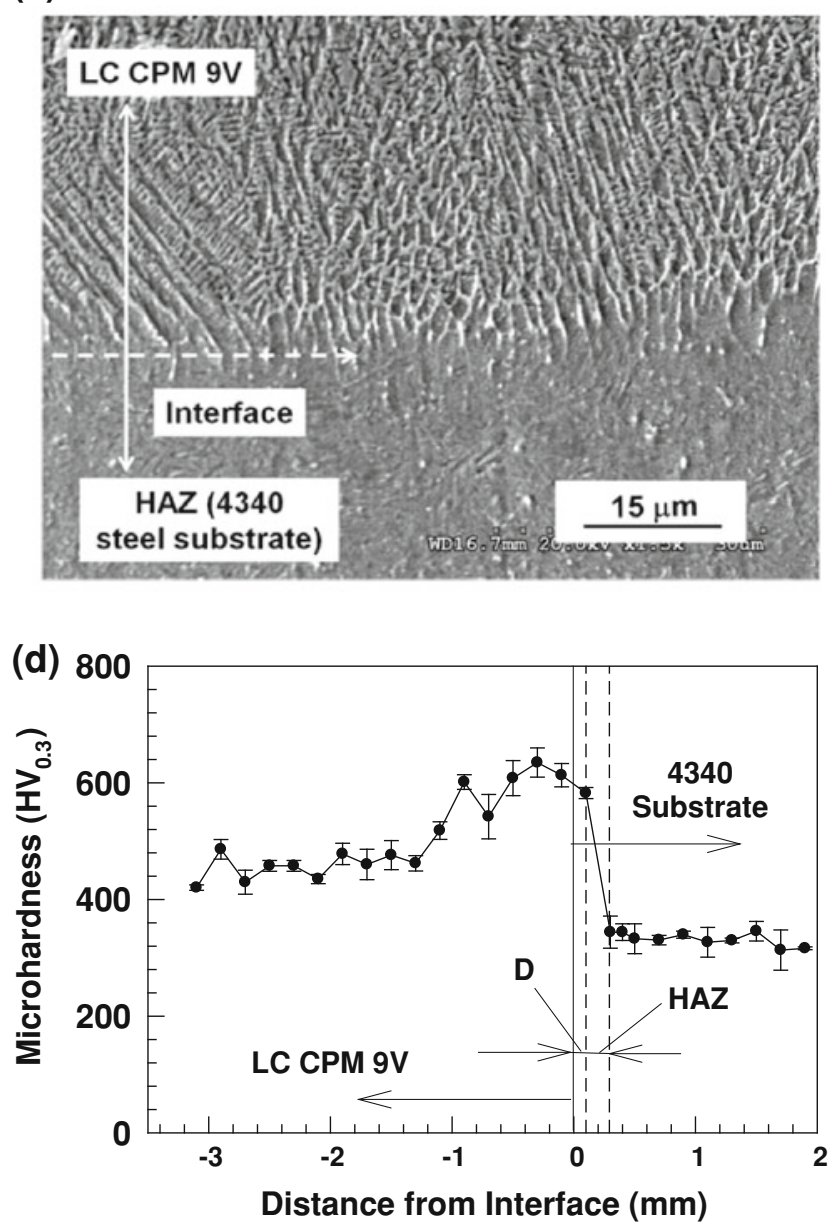

across the interface between the LC thin wall and the substrate, where $D$ depth of the penetration, and the HAZ heat-affected zone in the substrate

solidification phase would be austenitic $\gamma$ [35]. However, a high-rate solidification (such as, induced by laser deposition) would be kinetically favorable to the $\gamma$ as the primary solidification phase, even though the carbon content is $<1.3 \%$, in which with normal equilibrium solidification the primary phase should be ferritic $\delta$ instead $[36,37]$. Hence, the primary solidification phase for the LC CPM 9V steel (with a carbon content of about $1.8 \%$ ) should be austenitic $\gamma$, whereas the primary solidification phase for the LC H13 steel, which although the carbon content was $0.42 \%$, could be predominantly the metastable $\gamma$ phase as well due to the associated process-induced rapid solidification.

It could therefore reasonably assume that, for the LC H13 steel, the solidification of a molten pool started with the formation of a thin layer of fine austenitic nuclei at the solid/liquid interface due to the highly undercooling as a result of large thermal sink (i.e., the substrate), resulting in the formation of fine cellular structure. The latent heat so generated was rapidly and directionally dissipated through 
the solidified phase, along the maximum temperature gradient, to create a rapid directional solidification condition. Simultaneously supersaturated solute atoms were rejected from the solidifying austenitic phase into the melt ahead of the interface, creating a constitutionally undercooled molten layer ahead of the advancing solid/liquid interface, which could pose a perturbation at the prior stable interface and lead to formation of directional austenitic dendrites depending on the solidification rate [38]. When the subsequent layer was deposited, the continued epitaxial growth of the dendrites was less possible due to crystallographic difference (austenite/martensite); re-nucleation ahead of the solid/liquid interface in the melt formed a new fine cellular sub-layer, and continued to grow into a new sublayer of directional dendrites along the wall build-up direction, which was again completely constrained within the newly deposited layer.

In contrast, for the LC CPM 9V, except for the first several deposited layers where the similar solidification behavior as described in the LC H13 steel occurred (see Fig. 8c), fine equiaxed cellular-dominant structures prevailed instead (see Fig. 5b). While the cooling rate (thus temperature gradient) could be much higher for the initial several consolidated layers due to quicker heat dissipation to the bulk substrate, it became lower afterward as most part of heat during deposition was dissipated through the LC thin wall to the substrate, which decreased the temperature gradient and might lead to the formation of cellular-dominant solidified structure [39]. It is not clear what caused the difference of such a solidification behavior between the CPM 9V and the H13 steels, and a further research is needed to explore the thermal properties and thermal conditions during their solidification. In addition, the primary carbides in the LC CPM 9V steel were MC-type in eutectic form, whereas the rapid solidification seemingly favored the formation of MC-type of carbides (plus a small amount of $\mathrm{M}_{7} \mathrm{C}_{3}$ ) in the $\mathrm{LC} \mathrm{H13}$ steel as well [13].

After solidification, martensitic transformation of both LC steels could start as soon as the temperature dropped below their $M_{\mathrm{S}} \mathrm{s}$. However, according to Colaço and Vilar [36, 37, 40], a rapid solidification and a subsequent highrate cooling during laser deposition could bring $M_{\mathrm{s}}$ either up or down: a rapid cooling rate and a high dislocation density would raise the $M_{\mathrm{s}}$; whereas a supersaturation of alloying elements in the austenite, residual tensile stresses, and refined austenite grain size (if $<50 \mu \mathrm{m}$ ) would decrease the $M_{\mathrm{s}}$. Present XRD analysis confirmed both "as-consolidated" H13 and CPM 9V steels presented dominant martensitic $\alpha^{\prime}$ phase along with a small amount of retained austenitic $\gamma^{\prime}$ phase, which indicates that, overall, a martensitic transition indeed occurred in both steels before reaching to the ambient temperature no matter how their $M_{\mathrm{s}} \mathrm{s}$ were changed due to process-induced rapid solidification.

It is known that multiple thermal cycles induced by the "layer-upon-layer" laser deposition could produce heterogeneous microstructures in the LC steels that differ from region to region. Generally speaking, during depositing a new layer, a top portion of the previously deposited layer was re-melted and solidified together with the injected powder to form another "as-solidified" layer, while the microstructures under and adjacent to the re-melting area would be severely thermally affected, leading to solid-state phase transformations (i.e., progressive modification of the microstructures) depending on temperature gradient and phase stability $[13,36,37,40]$. Repeatedly, the prior deposited layers went through multiple thermal cycles, which finally tempered the major portion of the LC steels except the top several deposited layers of the thin wall. This is exactly the case for the LC H13 steel, which also agreed with the observation on the LENS- and DMDproduced H13 steels [9, 13, 17, 29, 30]. Comparatively, the LC CPM 9V steel acted slightly differently, the microstructure in the slightly "dark" region at the top of each deposited layer, which was thermally affected by the immediate deposition of the subsequent layer, exhibits partially dissolved eutectic phase at the inter-cellular regions due to re-austenitization during re-heating, but less affected by thermal-cycle-induced tempering.

\section{Mechanical Properties}

\section{Tensile Properties}

For "as-consolidated" H13 steel, the tensile strengths (average 2,064 and 2,033 MPa along and transverse to the wall build-up direction, respectively, as listed in Table 2) are comparable to that of the corresponding wrought $\mathrm{H} 13$ steel (about 1,999 MPa) [41]. More interestingly, in spite of as an "as-cast" microstructure, the ductility of the LC steel was only marginally lower than that of the wrought one. The "as-consolidated" steel exhibits some anisotropic tensile properties that could be related to microstructural anisotropy: the yield strength was about 1,288 $\mathrm{MPa}$ along the wall build-up direction, while it was about 1,564 $\mathrm{MPa}$ transverse to the wall build-up direction (Table 2). Since the residual stresses in the LC H13 steel are low [42], the main source of a higher yield strength transverse to the wall build-up direction than along the build-up direction, in this case, could be induced by much finer solidified structure along that direction (Fig. $7 b$ vs. a), which affected the deformability of the LC steel.

The "as-consolidated" CPM 9V steel has shown average yield strength of $821 \mathrm{MPa}$ and average tensile strength of 1,315 $\mathrm{MPa}$ along the wall build-up direction. Since the 
Table 2 Tensile properties of "as-consolidated" H13 and CPM 9V tool steels, where "L" represents the wall build-up direction, and " $\mathrm{T}$ " the transverse direction

\begin{tabular}{lllll}
\hline LC Material & Direction & $\sigma_{0.2}, \mathrm{MPa}$ & $\sigma_{\mathrm{UTS}}, \mathrm{MPa}$ & $\delta, \%$ \\
\hline "As-consolidated" H13 & $\mathrm{L}$ & $1,288 \pm 54$ & $2,064 \pm 51$ & $6.0 \pm 2.2$ \\
& $\mathrm{~T}$ & $1,564 \pm 24$ & $2,033 \pm 38$ & $5.0 \pm 2.8$ \\
& & 1,569 & 1,999 & 7.5 \\
$\begin{array}{l}\text { Wrought H13 (1038 }{ }^{\circ} \mathrm{C} \text { austenitizing }+ \\
482{ }^{\circ} \mathrm{C} \text { Tempering) [41] }\end{array}$ & $\mathrm{L}$ & $821 \pm 49$ & $1,315 \pm 29$ & $2.6 \pm 0.4$ \\
"As-consolidated" CPM 9V & & & & \\
\hline
\end{tabular}

metallographic study indicates no presence of any preferred crystallographic orientation, it might be reasonable to assume that the LC steel has comparable tensile properties in transverse direction as well.

The outstanding tensile properties of both LC tool steels may be due to the refined solidified structures induced by rapid solidification inherent to the process.

\section{Wear Resistances}

Figure 9(a) shows that, under the given test condition, the "as-consolidated" H13 steel has a significantly better sliding wear resistance as compared to the wrought H13 steel with different hardening treatments (i.e., austenitized at $1032{ }^{\circ} \mathrm{C}$ for $1 \mathrm{~h}$ and air quenched, and then tempered at 482 and $560{ }^{\circ} \mathrm{C}$ for $2 \mathrm{~h}$, respectively) as well as the annealed one $\left(880^{\circ} \mathrm{C}\right.$ for $1 \mathrm{~h}$, furnace cooling). The average wear loss of the "as-consolidated" H13 steel was about $0.14 \mathrm{~mm}^{3}$, which was only about the $1 / 3$ (or less) of those of the hardened wrought H13 steel (about $0.40-0.46 \mathrm{~mm}^{3}$ ), and only about one tenth of that of the annealed one (about $1.45 \mathrm{~mm}^{3}$ ). It is also interesting to note that the wear loss of the counterpart $\mathrm{Cr}$ steel ball against the "as-consolidated" H13 steel was significantly lower (about $0.21 \mathrm{~mm}^{3}$ ) than those against the wrought H13 steel (about $0.56-0.63 \mathrm{~mm}^{3}$ for the hardened ones and about $0.88 \mathrm{~mm}^{3}$ for the annealed one).

The obvious better sliding wear behavior, in terms of LC H13 steel, can be attributed to the high hardness as compared to the wrought one and the very fine microstructure. The hardness of the "as-consolidated" H13 steel was around HV 660 (equivalent to about HRC 58), which was higher than any hardened wrought H13 steel (about HRC 55 or less $[26,27])$. The very fine microstructure in the LC H13 steel might not only contribute to a higher wear resistance of itself but also result in a smoother wear scar (as compared to the ones against the wrought one), which was associated with less wear loss of the counter-body as a result.

The hardness of the LC H13 steel during tempering seems to be also fairly stable (Fig. 9b). The heat-treated LC steel retained its hardness in case of tempering at $400{ }^{\circ} \mathrm{C}$ for $2 \mathrm{~h}$; tempered at higher temperatures, its hardness was gradually getting lower with increased tempering temperature. Tempering slightly increased the wear volume losses
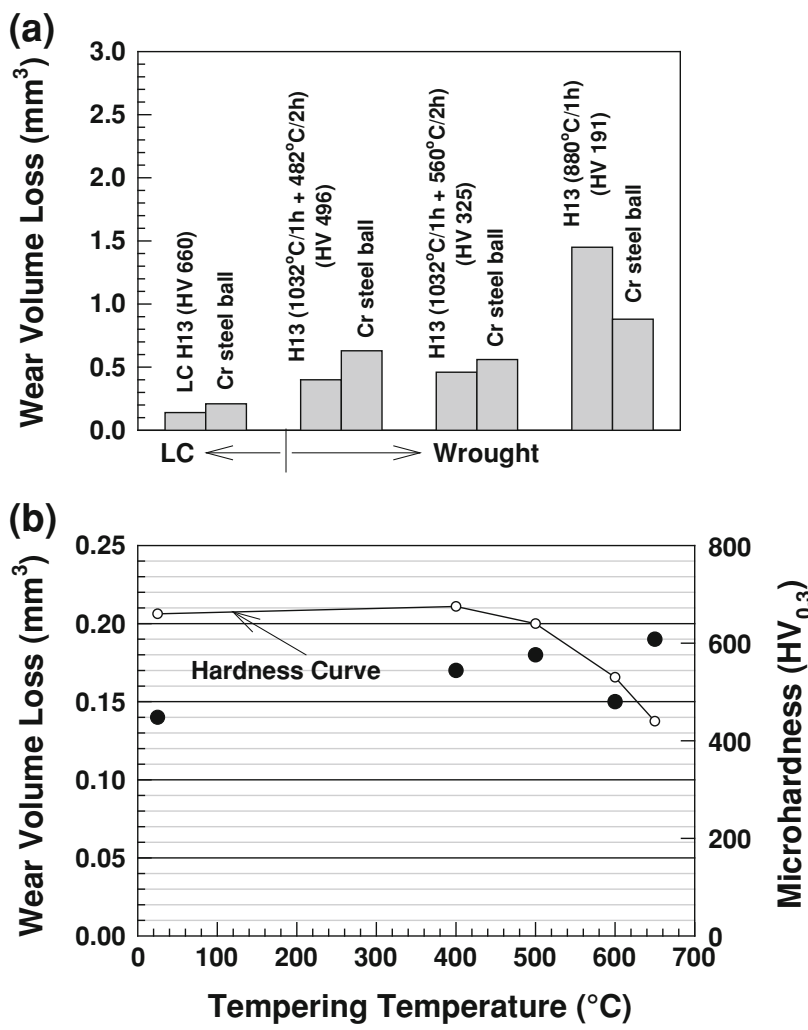

Fig. 9 Sliding wear losses of a "as-consolidated" H13 tool steel as compared to wrought $\mathrm{H} 13$ with different heat treatment conditions, and b "as-consolidated" $\mathrm{H} 13$ tool steel as compared to LC H13 under different tempering conditions, against $\mathrm{Cr}$ balls

of the LC H13 steel (overall, $<0.2 \mathrm{~mm}^{3}$ even after tempering at $650{ }^{\circ} \mathrm{C}$ for $2 \mathrm{~h}$ ) but still substantially better than that of the hardened wrought $\mathrm{H} 13$ steel (about $0.4 \mathrm{~mm}^{3}$ ).

For the LC CPM 9V steel (about HRC 49), the sliding wear resistance was significant better than that of the hardened wrought D2 tool steel (about HRC 62) and the normalized 4340 carbon steel (about HRC 35) (Fig. 10). The average wear loss of the "as-consolidated" steel $\left(0.02 \pm 0.01 \mathrm{~mm}^{3}\right)$ was only about the $1 / 3$ of the wear loss of the hardened D2 steel $\left(0.06 \pm 0.01 \mathrm{~mm}^{3}\right)$ and about one order of the magnitude of the normalized 4340 steel $\left(0.22 \pm 0.05 \mathrm{~mm}^{3}\right)$.

It should be noted that, in case of LC CPM $9 \mathrm{~V}$, as compared with conventional tool steels, the hardness is not the direct measure of the wear resistance. As detailed elsewhere [32], the vanadium carbides (in addition to the 


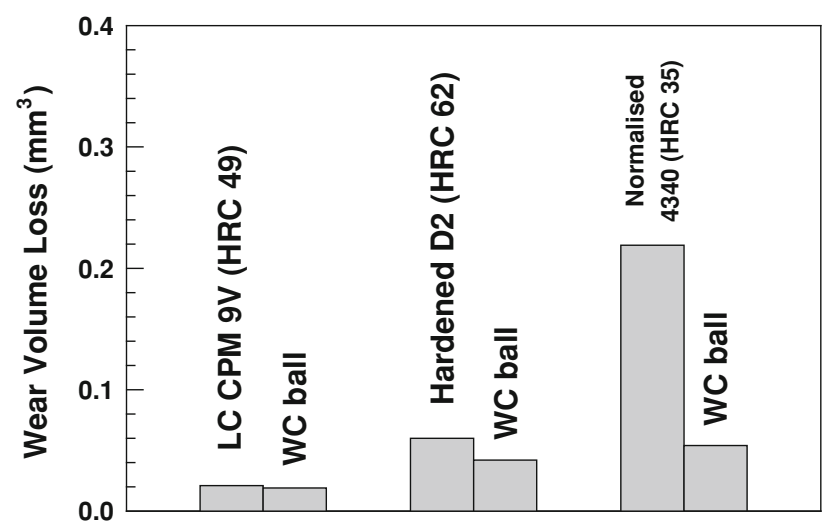

Fig. 10 Sliding wear losses of "as-consolidated" CPM 9V tool steel, hardened wrought D2 tool steel and normalized 4340 carbon steel, against WC balls

fine microstructure) in LC CPM 9V steel will account for the higher wear resistance in spite of the overall lower hardness as compared to D2 steel. It is believed that the vanadium-rich MC carbides are the hardest and therefore the most wear resistant, usually found in tool steels, as compared to the much less effective chromium-rich carbides (such as $\mathrm{M}_{7} \mathrm{C}_{3}$-type), which predominate in the $\mathrm{D} 2$ tool steel (almost 21 vol.\% [43]). The very fine microstructure in the LC CPM 9V steel should also result in a smoother wear scar and, thus, in a lower wear loss of the counter-body (the WC ball) as shown in Fig. 10, similar to what was observed in case of LC H13 steel.

Overall, based on the wear testing results, it is obvious that the LC H13 and CPM 9V steels exhibit not only high wear resistance of their own but also could reduce the wear rate of their counter-bodies. Those will be significantly beneficial factors for LC process for being potentially applied in TDM.

\section{Bonding Strengths}

The nominal bonding strength of the LC H13 steel onto hardened wrought $\mathrm{H} 13$ substrate according to the pull testing was about $1,102 \mathrm{MPa}$, which was close to the yield strength of the LC H13 steel along the wall build-up direction. Some of the coupons were broken at the gripping area instead (Fig. 11), which may be caused by the restriction in deformation at/near the interface due to the attached substrate.

Figure 12 depicts a relation between the mass impact energies (caused by cylindrical drop weight in a customized impact test apparatus, see Fig. 4a) and the failure at the interface between the "as-consolidated" thin-wall CPM $9 \mathrm{~V}$ blades and the normalized 4340 carbon steel substrates. For comparison, the impact resistances at the interface between the wrought thin-wall D2 tool steel blades

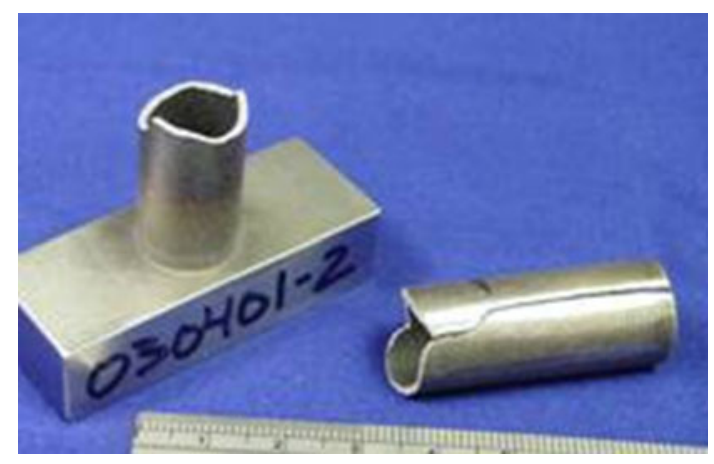

Fig. 11 Interfacial failure mode of "as-consolidated" H13 steel deposited on wrought H13 steel substrate after a bonding strength test

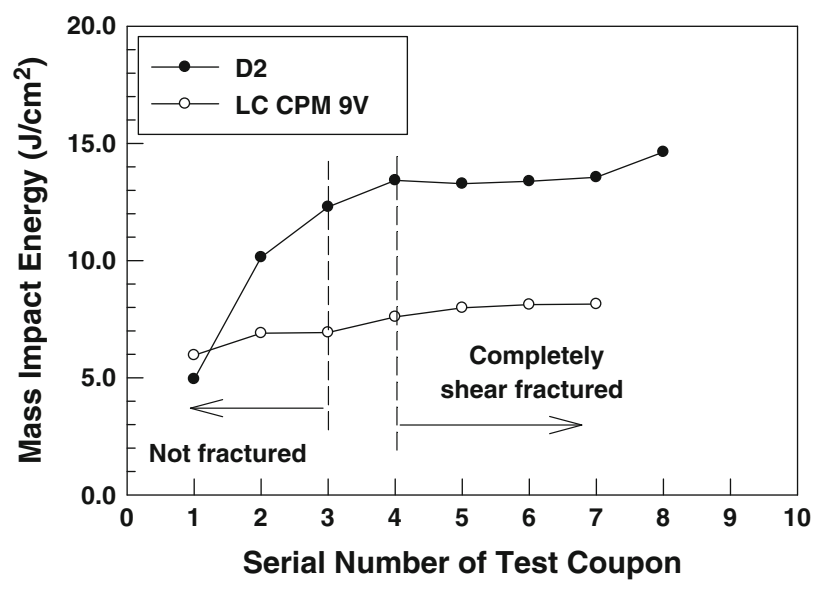

Fig. 12 Impact test results of "as-consolidated" thin-wall CPM 9V blade deposited on the normalized 4340 carbon steel substrate as compared to wrought thin-wall D2 blade machined out of the wrought bulk D2 substrate

(which were fully machined out of the bulk wrought D2 steel substrates) and the wrought D2 steel substrates were presented as well.

It could be seen that the bondline of the wrought thinwall D2 blade with the wrought D2 substrate remained unbroken when the mass impact energy was lower than $12.29 \mathrm{~J} / \mathrm{cm}^{2}$, while three out of four thin-wall D2 blades were completely fractured along the interface when the impact energy exceeded $13.28 \mathrm{~J} / \mathrm{cm}^{2}$. It was, hence, estimated that the resistance of the wrought thin-wall D2 blade on the wrought D2 substrate against the impact at the interface was roughly between 12.19 and $13.28 \mathrm{~J} / \mathrm{cm}^{2}$.

In contrast, the "as-consolidated" thin-wall CPM 9V blades exhibited no interfacial fracture when the impact energy of the mass was lower than $6.93 \mathrm{~J} / \mathrm{cm}^{2}$, but all "asconsolidated" thin-wall blades were completely detached from their substrates at the interface when the impact energy of the mass was higher than $7.6 \mathrm{~J} / \mathrm{cm}^{2}$. The interfacial resistance of the "as-consolidated" thin-wall CPM 
$9 \mathrm{~V}$ blade on the normalized 4340 substrate against the impact was, therefore, in the range of $7.0-7.6 \mathrm{~J} / \mathrm{cm}^{2}$.

In general, it could be seen that there was a sound bonding between the LC steel shape and the substrate. The bonding strength of LC H13 steel to wrought $\mathrm{H} 13$ steel is very promising as far as the application of $\mathrm{LC} \mathrm{H} 13$ is concerned. The impact resistance of LC CPM 9V steel bonded to the low alloy steel should be also considered promising, by reaching more than half of that between the machined D2 thin-wall blade and the bulk D2 steel substrate. The relatively inferior impact resistance in the case of LC CPM 9V steel may be possibly due to the combined effects of the "as-cast" microstructure, structural/compositional non-homogeneities at the interface, and the material difference itself.

\section{Conclusions}

By engaging LC process, "net-shape" functional shapes of H13 and CPM 9V tool steels can be built up through a "layer-upon-layer" deposition according to computeraided design (CAD) models. Current microstructural and mechanical investigations allow the following conclusions to be drawn:

(1) The LC tool steel shapes are metallurgically sound, free of cracks, possessing very fine microstructures inherently associated with process-induced rapid solidification. Both LC H13 and CPM 9V tool steels show layer-wise refined solidification structures, with dominated martensitic phase, and small amount of retained austenite as well as composition-dependent carbides.

(2) Mechanical properties as measured by tensile strength/strain and sliding wear resistance indicate that the LC shapes could be strongly bonded to the substrates and that the LC shapes could sometime outperform its wrought counterparts (as shown in the case of LC $\mathrm{H} 13$ tool steel) or other widely used conventional wrought tool steels such as D2 (as shown in the case of LC CPM 9V).

(3) In general, therefore, LC tool steel shapes (such as those of H13 and CPM 9V) could provide uniquely refined microstructures and excellent mechanical properties, which could be tailored for niche applications in materials additive manufacturing of TDM.

Acknowledgments The authors would like to acknowledge A. Theriault, B. Gibson, N. Santos, J. Fenner, M. Botros and M. Meinert for their important contributions to process development, specimen preparation, metallurgical characterization and mechanical testing.

\section{References}

1. C. Le Calvez, Rough Milling Characterization and Optimization of Steels for Plastic Injection Molds, Presented at the CIRP Workshop on Machining of Dies and Molds, Paris, 2001

2. B.A. Constantine, The Tubular Hydroforming of Advanced Steels and Aluminum: an Economic Evaluation Using Technical Cost Modeling, M.Sc. Thesis, McGill University, Montreal, Quebec, Canada, 1999

3. S.W. Hadley, S. Das, and J.W. Miller, Aluminum R\&D for Automotive Uses and the Department of Energy's Role, ORNL/ TM-1999/157, USA, 2000

4. E. Toyserkani, A. Khajepour, S. Corbin, Laser Cladding (CRC Press, Boca Raton, 2005), pp. 1-22

5. L. Costa, R. Vilar, Laser powder deposition. Rapid Prototyping J. 15(4), 264-279 (2009)

6. J.E. Smugeresky, D.M. Keicher, J.A. Romero, M.L. Griffith, and L.D. Harwell, Laser Engineered Net Shaping $\left(\right.$ LENS $^{\mathrm{TM}}$ ) Process: Optimization of Surface Finish and Microstructural Properties, DOC Report \#: SAND-97-8652C, USA, 1997

7. E. Schlienger, D. Dimos, M. Griffith, J. Michael, M. Oliver, Near Net Shape Production of Metal Components Using LENS, DOC Report \#: SAND-98-0664C, USA, 1998

8. G.K. Lewis, R.B. Nemec, J.O. Milewski, D.J. Thoma, M.R. Barbe, D.A. Cremers, Directed Light Fabrication, ICALEO'94, Orlando, FL, 1994, pp. 17-26

9. J. Mazumder, J. Choi, K. Nagarathnam, J. Koch, D. Hetzner, The direct metal deposition of $\mathrm{H} 13$ tool steel for 3-D components. JOM 49(5), 55-60 (1997)

10. J. Mazumder, A Crystal Ball View of Direct-Metal Deposition. JOM 52(12), 28-29 (2000)

11. M.L. Murphy, C. Lee, W.M. Steen, Studies in Rapid Prototyping by Laser Surface Cladding, ICALEO'93, Orlando, FL, 1993, pp 882-892

12. Y.P. Hu, C.W. Chen, K. Mukherjee, Development of a new laser cladding process for manufacturing cutting and stamping dies. J. Mater. Sci. 33(5), 1287-1292 (1998)

13. J. Brooks, C. Robino, T. Headley, S. Goods, M. Griffith, Microstructure and Property Optimization of LENS Deposited H13 Tool Steel, Proceedings of the Solid Freeform Fabrication Symposium., Austin, TX, 1999, pp. 375-382

14. S. Krause, An advanced repair technique: laser powder build-up welding. Sulzer Tech. Rev. 83(4), 4-6 (2001)

15. W. Jiang, P. Molian, Laser based flexible fabrication of functionally graded mould inserts. Int. J. Adv. Manuf. Technol. 19(9), 646-654 (2002)

16. L. Han, K.M. Phatak, F.W. Liou, Modeling of laser deposition and repair process. J. Laser Appl. 17(2), 89-99 (2005)

17. J. Choi, Y. Chang, Characteristics of laser aided direct metal/ material deposition process for tool steel. Int. J. Machine. Tools \& Manuf. 45(4-5), 597-607 (2005)

18. L. Costa, R. Vilar, T. Reti, A.M. Deus, Rapid tooling by laser powder deposition: process simulation using finite element analysis. Acta Mater. 53, 3987-3999 (2005)

19. Y. Xiong, J.E. Smugeresky, J.M. Schoenung, The influence of working distance on laser deposited WC-Co. J. Mater. Proc. Technol. 209, 4935-4941 (2009)

20. L. Wang, S.D. Felicelli, P. Pratt, Residual stresses in LENSdeposited AISI 410 stainless steel plates. Mater. Sci. Eng. A 496, 234-241 (2008)

21. F. Huang, Z. Jiang, X. Liu, J. Lian, L. Chen, Microstructure and properties of thin wall by laser cladding forming. J. Mater. Proc. Technol. 209(11), 4970-4976 (2009)

22. A.J. Pinkerton, L. Li, The effect of laser pulse width on multiplelayer $316 \mathrm{~L}$ steel clad microstructure and surface finish. Appl. Surf. Sci. 208-209, 411-416 (2003) 
23. P. Peyre, M. Gharbi, C. Gorny, M. Carin, S. Morville, D. Carron, P. Le Masson, T. Malot, R. Fabbro, Surface finish issues after direct metal deposition. Mater. Sci. Forum 706-709, 228-233 (2012)

24. L. Xue, M. Islam, Free-form laser consolidation for producing metallurgically sound and functional components. J. Laser Appl. 12(4), 160-165 (2000)

25. L. Xue, Laser Consolidation-A One-Step Manufacturing Process for Making Net-Shaped Functional Aerospace Components, SAE Document\#: 2006-01-3163, in Session: Additive Manufacturing in Aerospace Manufacturing \& Automated Fastening Conference \& Exhibition, September 12, 2006, Toulouse, France

26. AISI Type H13, Alloy Digest (Engineering Alloys Digest, Inc., Upper Montclair)

27. G. Roberts, G. Krauss, R. Kennedy, Tool Steels, 5th edn. (ASM International, Materials Park, OH, 1998), pp. 222-230

28. Crucible CPM 1V, 3V, 9V, 10V and 15V Datasheets, Crucible Industries $L L C$, www.crucibleservice.com

29. J. Koch, D. Hetzner, J. Mazumder, A Metallurgical Analysis of Laser-Clad H13, ICALEO'96, Orlando, FL, 1996, pp. A143A150

30. A.J. Pinkerton, L. Lin, Direct additive laser manufacturing using gas- and water-atomised H13 tool steel powders. Int. J. Adv. Manuf. Technol. 25, 471-479 (2005)

31. L. Xue, A. Theriault, J. Chen, M. Islam, A. Wieczorek, G. Draper, Laser Consolidation of CPM-9V Tool Steel for the Manufacturing of Rotary Cutting Dies, Processing and Fabrication of Advanced Materials X (PFAM X), Indianapolis, IN, 2001, pp. 361-376

32. S.-H. Wang, J. Chen, L. Xue, A study of the abrasive wear behaviour of laser-clad tool steel coatings. Surf. Coat. Technol. 200, 3446-3458 (2006)
33. J. Leunda, C. Soriano, C. Sanz, N.V. García, Laser cladding of vanadium-carbide tool steels for die repair. Phys. Procedia 12(A), 345-352 (2011)

34. J. Chen, L. Xue, Laser cladding of CPM tool steels on hardened H13 hot-work steel for low-cost high-performance automotive tooling. JOM 64(6), 688-693 (2012)

35. M. Boccalini, H. Goldenstein, Solidification of high speed steels. Int. Mater. Rev. 46(2), 92-115 (2001)

36. R. Colaço, R. Vilar, Effect of the processing parameters on the proportion of retained austenite in laser surface melted tool steels. J. Mater. Sci. Lett. 17, 563-567 (1998)

37. R. Colaço, R. Vilar, Stabilisation of retained austenite in laser surface melted tool steels. Mater. Sci. Eng. A 385(1-2), 123-127 (2004)

38. N.H. Pryds, Rapid Solidification of the 12\%Cr Steel, Ris $\phi-R-992$ (EN) (Risø National Laboratory, Roskile, 1997), p. 29

39. I. Hemmati, V. Ocelík, JThM De Hosson, Microstructural characterization of AISI 431 martensitic stainless steel laser-deposited coatings. J. Mater. Sci. 46(10), 3405-3414 (2011)

40. L. Costa, R. Vilar, T. Reti, R. Colaço, A.M. Deus, I. Felde, Simulation of phase transformations in steel parts produced by laser powder deposition. Mater. Sci. Forum 473-474, 315-320 (2005)

41. ASM International Handbook Committee, Metals Handbook, vol. 1 (ASM International, Material Park, OH, 1990), p. 442

42. J. Chen, L. Xue, Comparison study of H13 tool steel microstructure produced by laser cladding and laser consolidation, Symposium on Near-Net-Shape Technologies in MS\&T'05, Pittsburgh, PA, 2005, pp. 23-31

43. W. Stasko, K.E. Pinnow, R.B. Dixon, Particle Metallurgy Cold Work Tool Steels Containing 3-18\% Vanadium, Metal Powder Industries Federation: Advanced Particulate Materials and Processes. USA, 1997, pp. 401-409 